\title{
Optimization and sliding mode control of dividing-wall column
}

\author{
Honghai Wang a, c, *, Zhongbiao Wang ${ }^{\text {a, c }}$, Qi Zhou ${ }^{\text {a, c }}$, Jun Liang ${ }^{\text {a, c }}$, Yi Yin ${ }^{\text {a, c }}$, \\ Weiyi $\mathrm{Su}^{\mathrm{a}, \mathrm{c}}$, and Guangyan Wang $\mathrm{b}, *$ \\ ${ }^{a}$ School of Chemical Engineering and Technology, Hebei University of Technology, Tianjin, 300130, \\ China \\ ${ }^{b}$ School of Information Engineering, Tianjin University of Commerce, Tianjin, 300134, China \\ ${ }^{\mathrm{c}}$ National-Local Joint Engineering Laboratory for Energy Conservation in Chemical Process Integration \\ and Resources Utilization, School of Chemical Engineering and Technology, Hebei University of \\ Technology, Tianjin, 300130, China \\ *Corresponding author: Honghai Wang e-mail: ctstwhh@hebut.edu.cn \\ Guangyan Wang e-mail:guangyan75@163.com
}




\section{Supporting Information:}

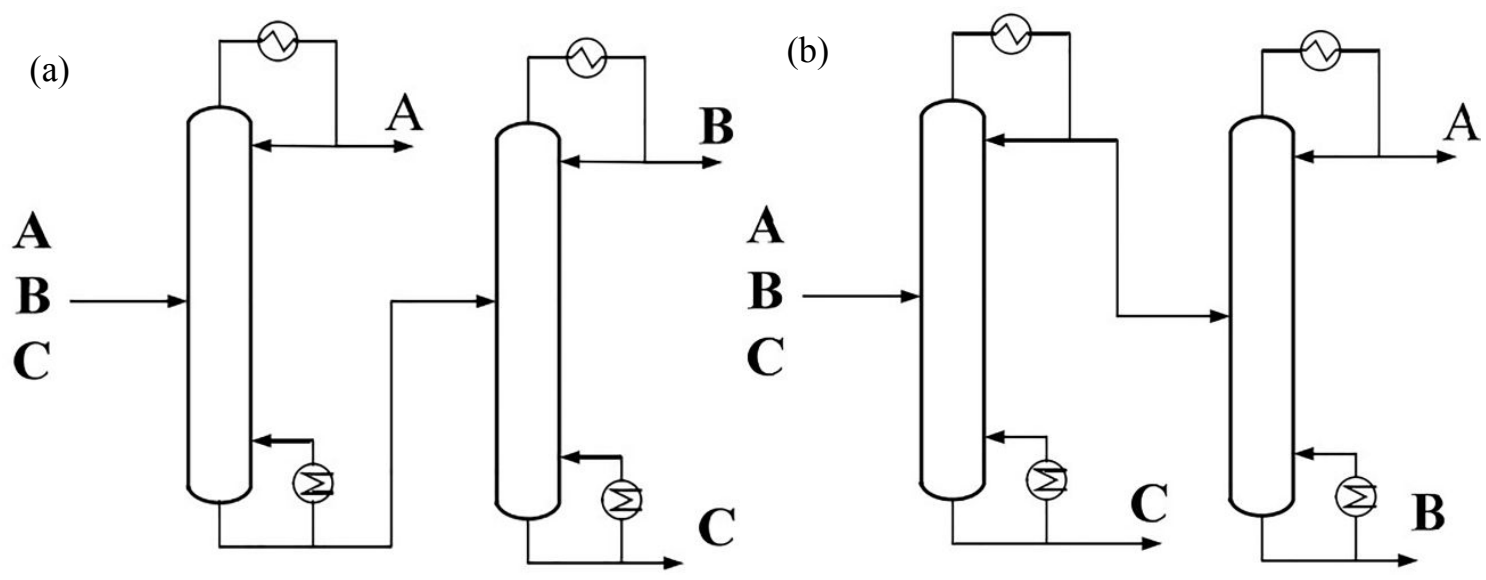

Figure S1. Traditional direct distillation sequence (a) and Traditional indirect distillation sequence (b)

Table S1. The level code for each variable in the BBD and corresponding production response of $\mathrm{C}_{5}, \mathrm{C}_{6}, \mathrm{C}_{7}$, and $\mathrm{Q}$

\begin{tabular}{|c|c|c|c|c|c|c|c|c|}
\hline Run & $\begin{array}{l}\text { Factor1 } \\
\text { A: NF }\end{array}$ & $\begin{array}{c}\text { Factor2 } \\
\text { B: R }\end{array}$ & $\begin{array}{l}\text { Factor3 } \\
\text { C: SPL }\end{array}$ & $\begin{array}{l}\text { Factor4 } \\
\text { D: SPV }\end{array}$ & $\begin{array}{c}\text { Response } 1 \\
\mathrm{C}_{5}\end{array}$ & $\begin{array}{c}\text { Response } 2 \\
\mathrm{C}_{6}\end{array}$ & $\begin{array}{c}\text { Response } 3 \\
\mathrm{C}_{7}\end{array}$ & $\begin{array}{c}\text { Response4 } \\
\text { Q }\end{array}$ \\
\hline 1 & 9.00 & 7.00 & 0.50 & 0.70 & 0.99024 & 0.988783 & 0.998543 & 643.596 \\
\hline 2 & 5.00 & 7.00 & 0.50 & 0.70 & 0.990406 & 0.985082 & 0.994676 & 643.424 \\
\hline 3 & 9.00 & 7.50 & 0.50 & 0.65 & 0.995814 & 0.99206 & 0.996255 & 679.394 \\
\hline 4 & 7.00 & 7.00 & 0.50 & 0.65 & 0.996004 & 0.990494 & 0.9945 & 641.857 \\
\hline 5 & 7.00 & 7.50 & 0.50 & 0.70 & 0.990039 & 0.988052 & 0.998015 & 681.158 \\
\hline 6 & 5.00 & 7.50 & 0.50 & 0.65 & 0.9959 & 0.991429 & 0.995525 & 679.342 \\
\hline 7 & 9.00 & 7.00 & 0.55 & 0.65 & 0.997989 & 0.984016 & 0.986029 & 641.416 \\
\hline 8 & 5.00 & 7.00 & 0.45 & 0.65 & 0.993387 & 0.987846 & 0.994459 & 642.264 \\
\hline 9 & 7.00 & 7.00 & 0.55 & 0.60 & 0.999387 & 0.97424 & 0.97487 & 640.457 \\
\hline 10 & 5.00 & 7.00 & 0.55 & 0.65 & 0.99807 & 0.983981 & 0.985935 & 641.394 \\
\hline 11 & 7.00 & 7.50 & 0.55 & 0.65 & 0.997906 & 0.987147 & 0.989239 & 678.927 \\
\hline 12 & 5.00 & 7.00 & 0.50 & 0.60 & 0.99851 & 0.985499 & 0.986973 & 640.761 \\
\hline 13 & 7.00 & 7.50 & 0.50 & 0.60 & 0.998378 & 0.988256 & 0.989861 & 678.208 \\
\hline 14 & 7.00 & 6.50 & 0.45 & 0.65 & 0.993453 & 0.990641 & 0.997209 & 604.857 \\
\hline 15 & 7.00 & 7.00 & 0.55 & 0.70 & 0.994411 & 0.989193 & 0.994778 & 642.748 \\
\hline 16 & 7.00 & 7.50 & 0.45 & 0.65 & 0.993087 & 0.990964 & 0.99788 & 679.903 \\
\hline 17 & 7.00 & 7.00 & 0.45 & 0.70 & 0.983977 & 0.979113 & 0.995135 & 644.555 \\
\hline 18 & 7.00 & 6.50 & 0.50 & 0.70 & 0.990509 & 0.988163 & 0.997663 & 605.948 \\
\hline 19 & 7.00 & 6.50 & 0.55 & 0.65 & 0.998169 & 0.979934 & 0.981763 & 603.902 \\
\hline 20 & 9.00 & 6.50 & 0.50 & 0.65 & 0.996144 & 0.988367 & 0.992226 & 604.347 \\
\hline 21 & 9.00 & 7.00 & 0.50 & 0.60 & 0.998383 & 0.98559 & 0.987207 & 640.766 \\
\hline 22 & 7.00 & 7.00 & 0.45 & 0.60 & 0.99701 & 0.991277 & 0.994269 & 641.064 \\
\hline
\end{tabular}




\begin{tabular}{rrrrrrrrr}
\hline 23 & 7.00 & 7.00 & 0.50 & 0.65 & 0.996004 & 0.990494 & 0.9945 & 641.857 \\
24 & 7.00 & 7.00 & 0.50 & 0.65 & 0.996004 & 0.990494 & 0.9945 & 641.857 \\
25 & 5.00 & 6.50 & 0.50 & 0.65 & 0.996248 & 0.987962 & 0.991715 & 604.311 \\
26 & 9.00 & 7.00 & 0.45 & 0.65 & 0.993221 & 0.991624 & 0.998402 & 642.428 \\
27 & 7.00 & 7.00 & 0.50 & 0.65 & 0.996004 & 0.990494 & 0.9945 & 641.857 \\
28 & 7.00 & 6.50 & 0.50 & 0.60 & 0.9986 & 0.981951 & 0.983352 & 603.289 \\
29 & 7.00 & 7.00 & 0.50 & 0.65 & 0.996004 & 0.990494 & 0.9945 & 641.857 \\
\hline
\end{tabular}

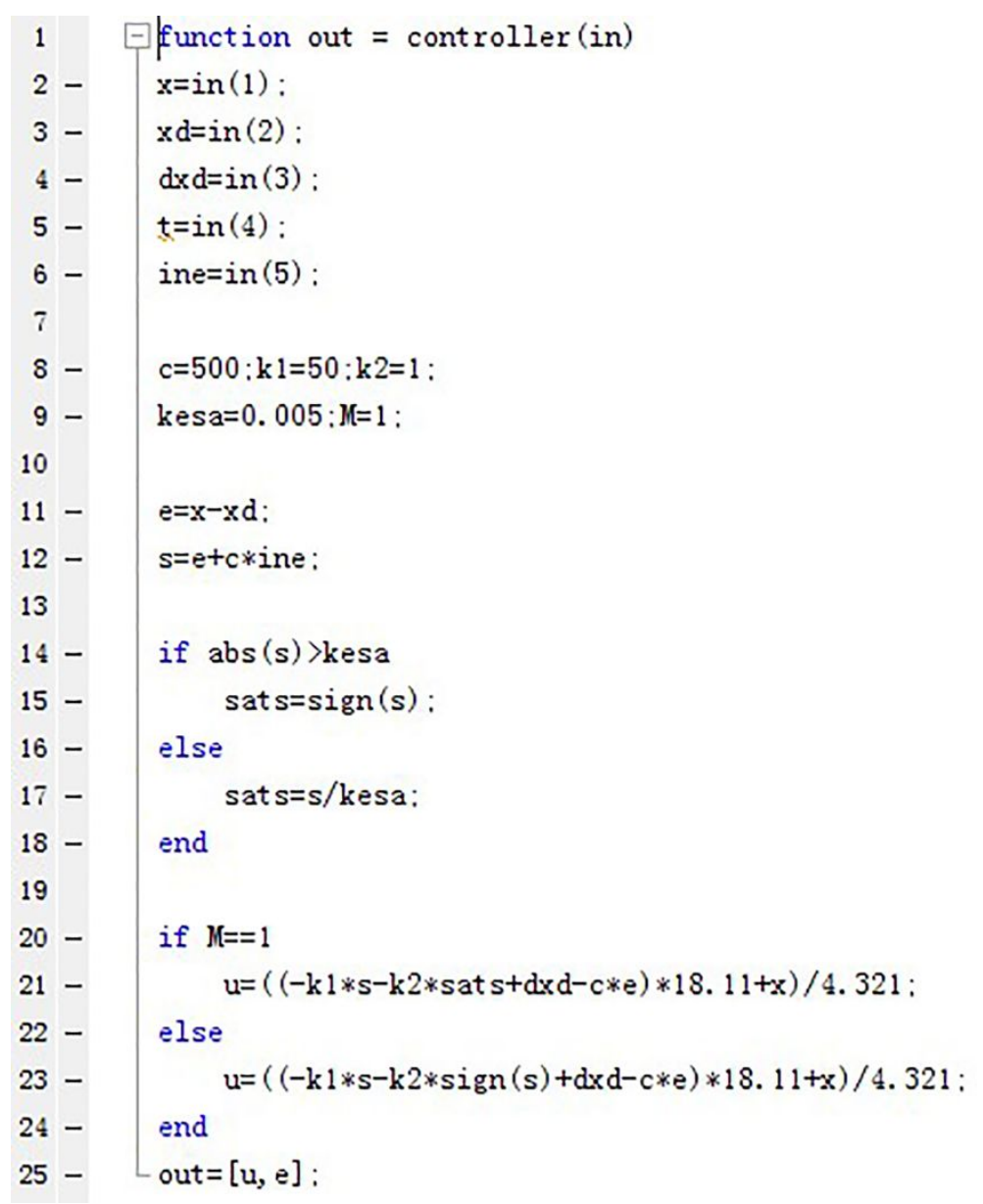

Figure S2. Interpreted MATLAB Fen of MATLAB/Simulink for the SMC strategy. 


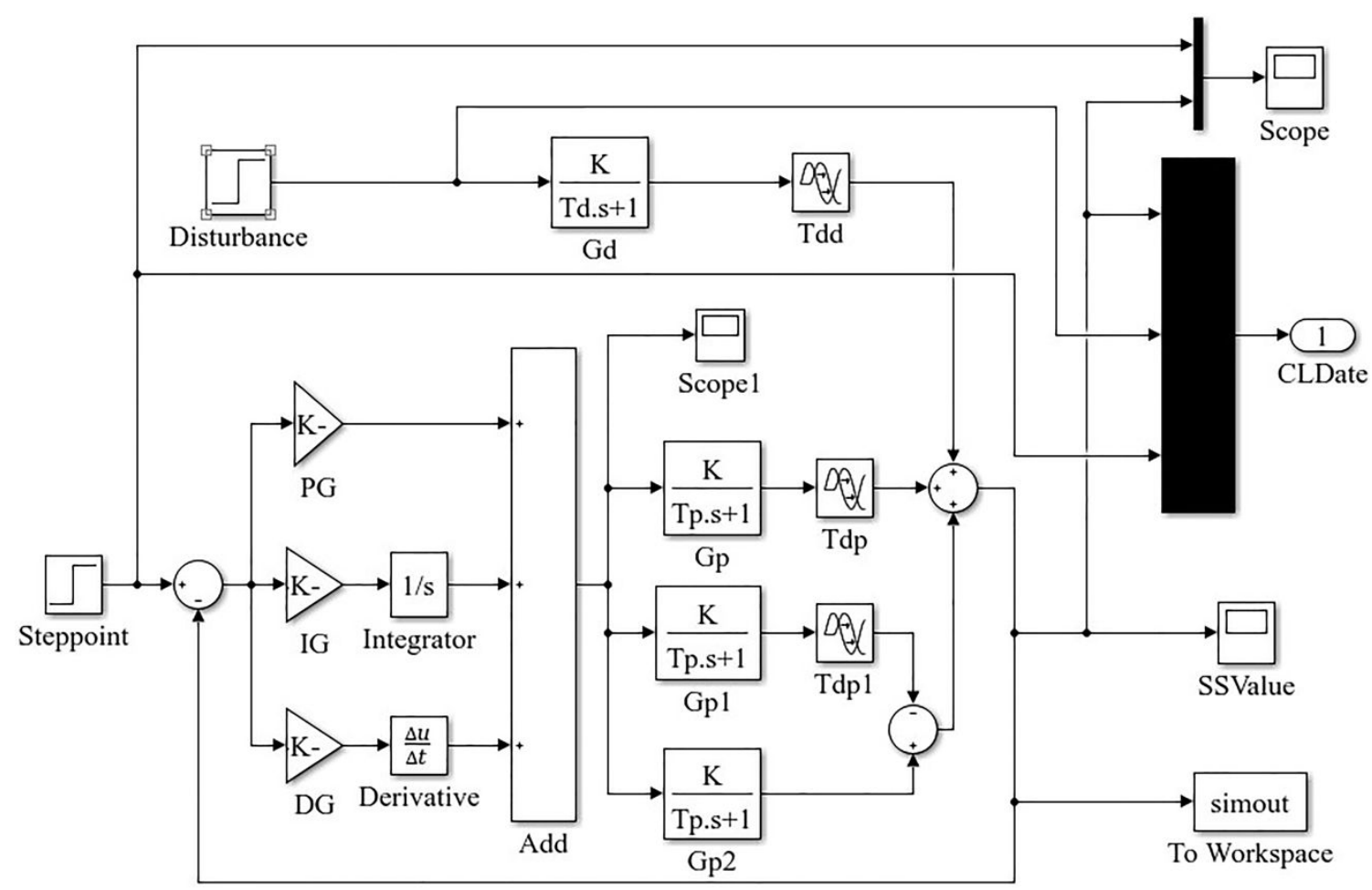

Figure S3. Simulink model of the DWC system for PID control

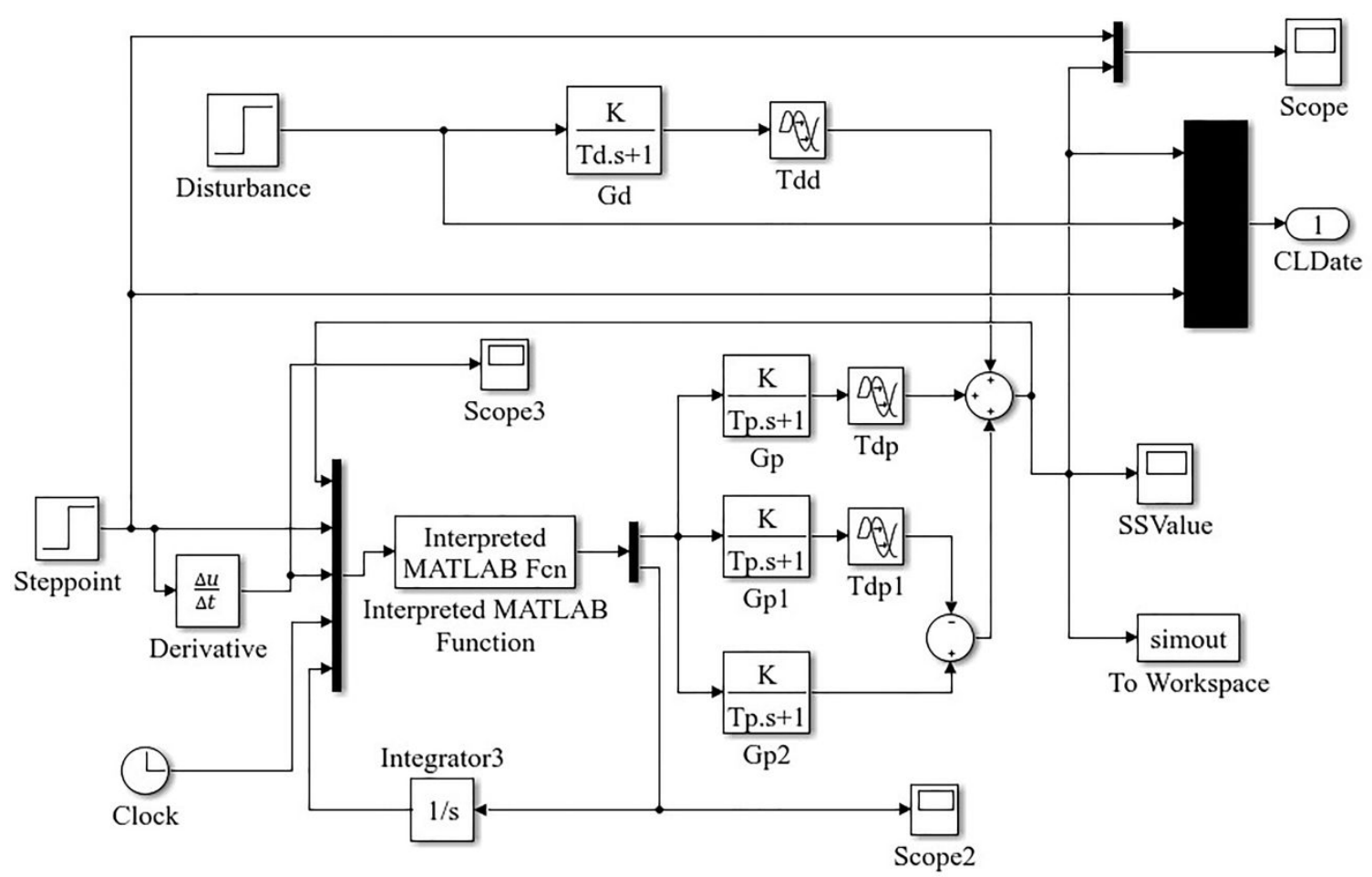

Figure S4. Simulink model of the DWC system for SMC control 


\section{APPENDIX}

Actually, this paper mainly focuses on the theoretical research of applying SMC in DWC system for the first time. Therefore, we choose an ideal hydrocarbon mixture as in the literature to complete the theoretical study, hoping to provide a reference for the application of SMC in more industrial systems in the future. Even though the ideal mixture of hydrocarbon is not practical, it can be used to compare the performance of different control strategies somehow.

In order to allow a fair comparison, we studied the industrially relevant ternary separation of the mixture benzene-toluene-xylene (BTX) in a DWC. The dynamic responses of the set-point tracking for the mole fraction of composition in the closed-loop control system of the DWC are shown in Figure S5. It can be seen that SMC performed nearly the same as for the ideal mixtures of hydrocarbon. Therefore, we can see that SMC performed better than PID in the control of DWC even for more industrial materials.

(a)

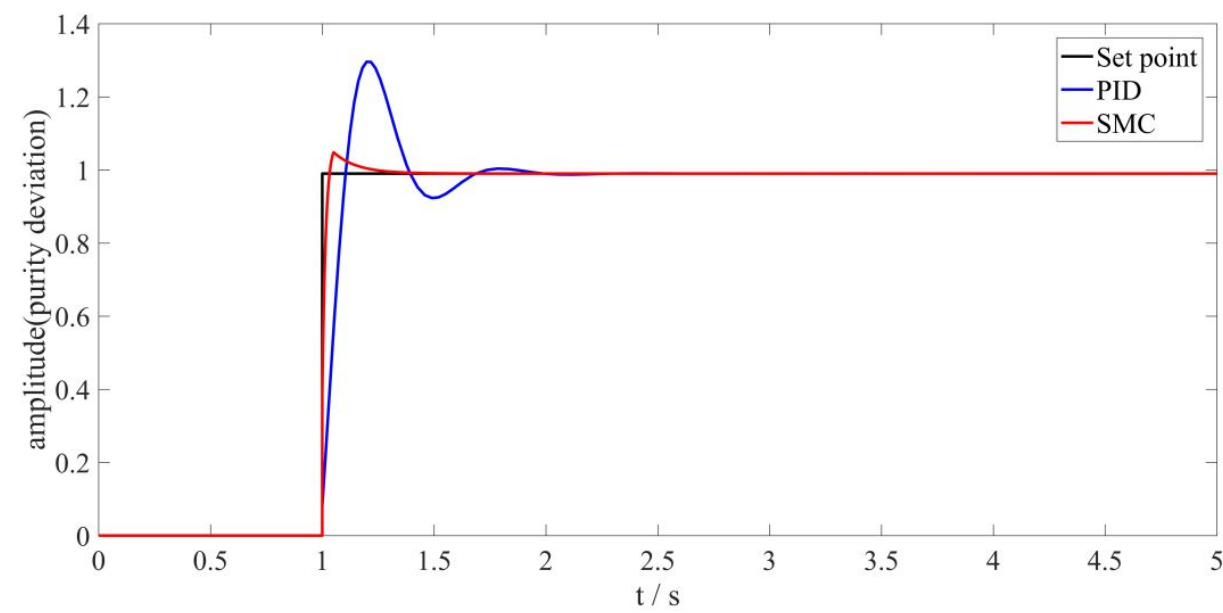




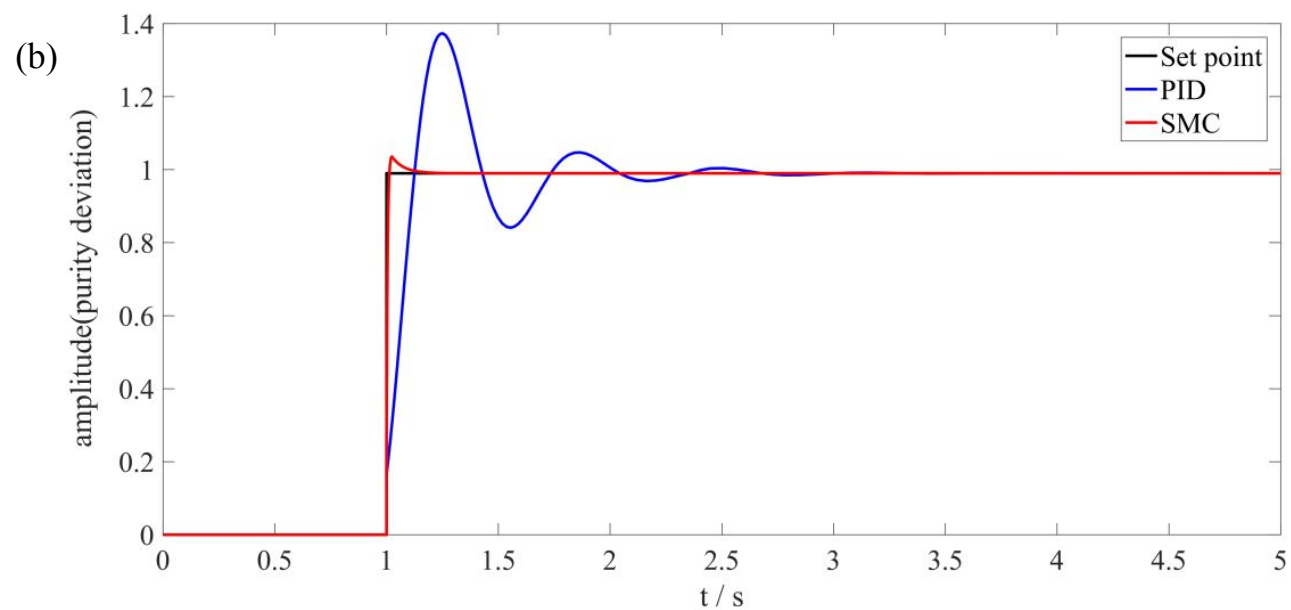

(c)

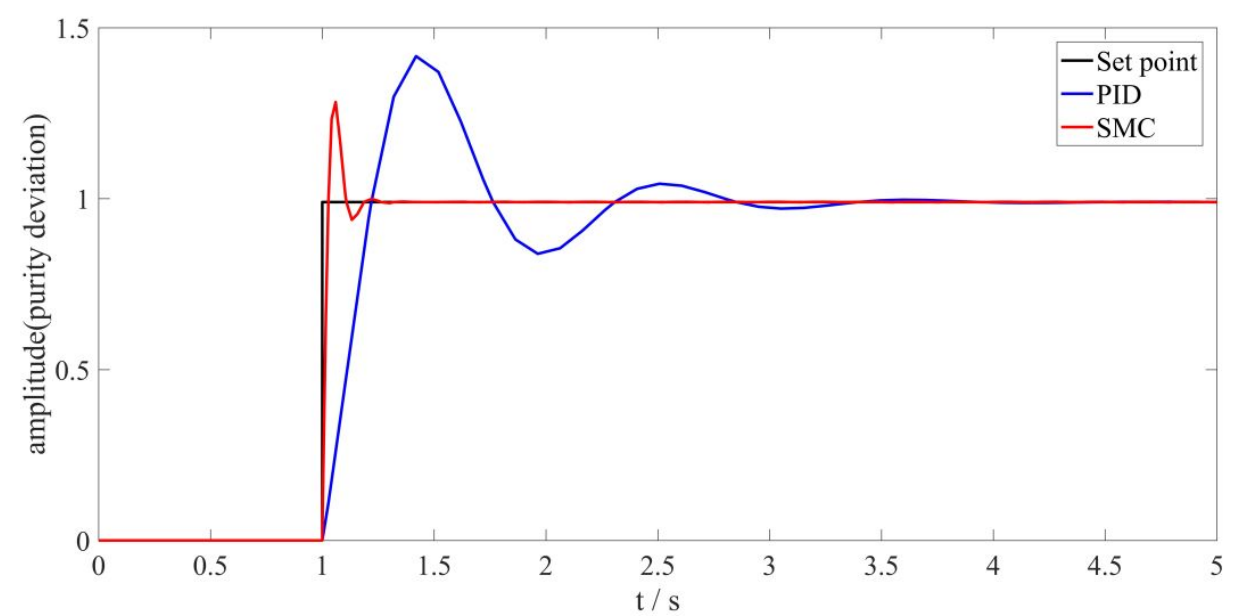

Figure S5. The comparison of SMC and PID controllers in DWC for the separation of benzene (a), toluene (b), and xylene (c) 